\title{
Toll-like receptor-dependent production of IL-12p40 causes chronic enterocolitis in myeloid cell-specific Stat3-deficient mice
}

\author{
Masaya Kobayashi, ${ }^{1}$ Mi-Na Kweon, ${ }^{2}$ Hirotaka Kuwata, ${ }^{1}$ Robert D. Schreiber, ${ }^{3}$ \\ Hiroshi Kiyono, ${ }^{2,4}$ Kiyoshi Takeda, ${ }^{1,5}$ and Shizuo Akira ${ }^{1,5}$ \\ ${ }^{1}$ Department of Host Defense, Research Institute for Microbial Diseases, Osaka University, Osaka, Japan \\ ${ }^{2}$ Department of Mucosal Immunology, Research Institute for Microbial Diseases, Osaka University, Osaka, Japan \\ ${ }^{3}$ Department of Pathology and Immunology, Center for Immunology, School of Medicine, Washington University, \\ St. Louis, Missouri, USA \\ ${ }^{4}$ Division of Mucosal Immunology, Institute of Medical Science, The University of Tokyo, Tokyo, Japan \\ ${ }^{5}$ Solution Oriented Research for Science and Technology, Japan Science and Technology Corp., Tokyo, Japan
}

Stat3 plays an essential role in IL-10 signaling pathways. A myeloid cell-specific deletion of Stat3 resulted in inflammatory cytokine production and development of chronic enterocolitis with enhanced Th1 responses in mice. In this study, we analyzed the mechanism by which a Stat 3 deficiency in myeloid cells led to the induction of chronic enterocolitis in vivo. Even in the absence of Stat 1 , which is essential for IFN- $\gamma$ signaling pathways, Stat 3 mutant mice developed chronic enterocolitis. TNF- $\alpha /$ Stat 3 double-mutant mice developed severe chronic enterocolitis with enhanced Th1 cell development. IL-12p40/Stat 3 double-mutant mice, however, showed normal Th1 responses and no inflammatory change in the colon. RAG2/Stat3 double-mutant mice did not develop enterocolitis, either. These findings indicate that overproduction of IL-12p40, which induces potent Th1 responses, is essential for the development of chronic enterocolitis in Stat3 mutant mice. Furthermore, enterocolitis was significantly improved and IFN- $\gamma$ production by $T$ cells was reduced in TLR4/Stat3 double-mutant mice, indicating that TLR4-mediated recognition of microbial components triggers aberrant IL-12p40 production by myeloid cells, leading to the development of enterocolitis. Thus, this study clearly established a sequential innate and acquired immune mechanism for the development of Th1-dependent enterocolitis.

J. Clin. Invest. 111:1297-1308 (2003). doi:10.1172/JCI200317085.

\section{Introduction}

Human inflammatory bowel diseases (IBD) including Crohn diseases and ulcerative colitis are chronic immune-mediated disorders whose pathogenesis and etiology are largely unknown (1). A number of genemanipulated murine models of colitis have been developed. These include IL-10-deficient, T cell receptor$\alpha$-deficient, Goi2-deficient, Stat4-transgenic, and T-bet-transgenic mice (2-5). Experimentally induced models of colitis have also been established by reconstituting immunocompromised mice with $\mathrm{CD}^{+}$ CD45RB high $\mathrm{T}$ cells. All of these models are used in

Received for publication October 8, 2002, and accepted in revised form January 28, 2003.

Address correspondence to: Shizuo Akira, Department of Host Defense, Research Institute for Microbial Diseases, Osaka University, 3-1 Yamada-oka, Suita Osaka 565-0871, Japan. Phone: 81-6-6879-8302; Fax: 81-6-6879-8305;

E-mail: sakira@biken.osaka-u.ac.jp.

Conflict of interest: The authors have declared that no conflict of interest exists.

Nonstandard abbreviations used: inflammatory bowel diseases (IBD); phycoerythrin (PE); Toll-like receptor 4 (TLR4). attempts to elucidate the pathogenesis of IBD. As a result, it has been proposed that an exaggerated bias toward Th1 or Th2 polarization in the mucosal immune system is a key factor in the pathogenesis of colitis $(6,7)$.

In IL-10-deficient mice, $\mathrm{CD} 4^{+} \mathrm{T}$ cells residing in the lamina propria region of intestinal tract preferentially produced IFN- $\gamma$ (8). Immunocompromised mice transferred with T cells from IL-10-deficient mice developed colitis with skewed Th1 responses (9). Furthermore, treatment with anti-IFN- $\gamma$ Ab significantly delayed the onset of the disease and reduced the severity of colitis in young IL-10-deficient mice (8). Treatment of anti-IL-12 $\mathrm{Ab}$ prevented the development of the disease in young IL-10-deficient, but not in aged IL-10-deficient, mice (7, 10). Thus, the involvement of Th1 cells has become clear in the pathogenesis of early phase of colitis in IL-10-deficient mice. IL-10 is a well-known regulatory cytokine, which can provide positive and negative signals on a variety of immune cells including B cells, T cells, NK cells, mast cells, and myeloid cells (11). Additionally, IL-10 has recently been shown to play an important role in the differentiation and function of regulatory $\mathrm{T}$ cells, which possess a capacity to inhibit harmful immune disorders including chronic colitis $(12,13)$. Although it is now 
clear that IL-10 plays an essential role in the negative regulation of inflammatory responses in the intestine, the mechanism by which IL-10 exerts the anti-inflammatory responses remains unclear.

The STAT family of transcription factors, consisting of seven members, is involved in cytokine signaling. The knockout of each member of the STAT family in mice resulted in impaired responses to corresponding cytokines, demonstrating that STAT proteins have essential roles in cytokine-mediated biological responses $(14,15)$. Unlike the knockout of all other STAT family members, the knockout of Stat3 resulted in early death in embryogenesis (16). Therefore, Stat3 has been deleted in a cell- or tissue-specific manner by the Cre-loxP recombination system in order to examine biological and functional roles of the transcription factor in vivo (17-19). For example, mice lacking Stat3 in myeloid cells such as macrophages, neutrophils, and dendritic cells developed chronic enterocolitis and showed exaggerated Th1 responses (20). The immunological and histological analysis revealed very similar disease development in the intestinal tract of IL-10-deficient mice. Macrophages from the Stat3 mutant mice did not show any anti-inflammatory responses mediated by IL-10 and produced increased levels of inflammatory cytokines in response to bacterial LPS, demonstrating that Stat 3 is essential for the IL-10-mediated signaling pathways in myeloid cells (20). This study also indicated that myeloid cells, including macrophages and dendritic cells, are major targets for IL-10 exhibiting anti-inflammatory responses in vivo, and the abnormal activation of myeloid cells is involved in the pathogenesis of chronic colitis in mice. It remains elusive, however, how the abnormal activation of myeloid cells leads to the development of colitis in vivo.

In this study, we examined the in vivo mechanism by which activated myeloid cells in the absence of IL-10 signaling induce chronic colitis using Stat 3 mutant mice with additional deleted alleles, such as Stat 1, TNF- $\alpha$, IL-12p40, RAG2, and Toll-like receptor 4 (TLR4).

\section{Methods}

Mice. Stat 3 mutant (LysMcre; Stat $3 f^{f l o x}$ flox) mice on a mixed $129 \times \mathrm{C} 57 \mathrm{BL} / 6$ genetic background (backcrossed to C57BL/ 6 for three generations) were used in this study $(17,20)$. Stat1-deficient mice on a C57BL/6 background were mated with Stat 3 mutant mice (21). TNF- $\alpha$-deficient and IL-12p40-deficient mice on a C57BL/ 6 background were kindly provided by K. Sekikawa and J. Magram, respectively $(22,23)$. RAG2-deficient mice on a C57BL/ 6 background were kindly provided by Fred Alt (Harvard Medical School and Center for Blood Research, Boston, Massachusetts, USA). TLR4-deficient mice were generated as described previously (24). Littermate wildtype or heterozygous mutant mice were used for experiments as control mice. All mice were housed in a specific pathogen-free facility at the Research Institute for Microbial Diseases, Osaka University (Osaka, Japan).
Histopathological analysis. Paraffin-embedded colon samples were sectioned and stained with H\&E. Transverse sections are shown in the figures. Severity of colitis was evaluated by the standard scoring system as described previously (25). Each region of the colon (cecum; ascending, transverse, and descending colon; and rectum) was graded semiquantitatively from 0 (no change) to 5 (most severe change). The grading represents an increasing incidence and degree of inflammation, goblet cell loss, crypt abscesses and ulceration, and fibrosis in the lamina propria. The summation of the score for each segment of the colon provides a total disease score per mouse $(0-25)$ where: 0 indicates no change; $1-5$, mild disease; $6-10$, mild-moderate; and $11-20$, severe. No mice in these studies had a score above 20 because such severe disease results in death. The scoring was performed blinded manner by two independent investigators. The colitis scores were evaluated using the program Statview II (SAS Inc., Cary, North Carolina, USA). $P$ values less than 0.05 were assumed to be statistically significant.

Cytokine production by macrophages. Mice were intraperitoneally injected with $2 \mathrm{ml}$ of $4 \%$ thioglycollate medium (Sigma-Aldrich, St. Louis, Missouri, USA). Three days later, peritoneal exudate cells were isolated from the peritoneal cavity by washing with ice-cold HBSS (Sigma-Aldrich). Cells were cultured for $2 \mathrm{~h}$ and washed with HBSS to remove nonadherent cells. Adherent monolayer cells were used as peritoneal macrophages. Peritoneal macrophages were cultured with $10 \mathrm{ng} / \mathrm{ml}$ of LPS (Escherichia coli serotype O55:B5), $1 \mu \mathrm{M}$ of CPG DNA, or $50 \mathrm{U} / \mathrm{ml}$ of IFN- $\gamma$ (Genzyme, Cambridge, Massachusetts, USA) plus LPS for $24 \mathrm{~h}$. Concentrations of TNF- $\alpha$, IL-6, and IL-12p40 in the culture supernatants were measured by ELISA according to the manufacturer's instructions (Genzyme; Endogen Inc., Woburn, Massachusetts, USA). Production of nitric oxide was measured by the Greiss method using a $\mathrm{NO}_{2} / \mathrm{NO}_{3}$ Assay Kit (DOJINDO, Kumamto, Japan).

Cytokine production by dendritic cells isolated from the large intestine. The large intestine was removed aseptically. After removal of colonic patches, the large intestine was washed with RPMI-1640 on ice and stirred with RPMI- 1640 containing $20 \mathrm{mM}$ HEPES, $50 \mu \mathrm{g} / \mathrm{ml}$ of gentamycin, $100 \mathrm{U} / \mathrm{ml}$ penicillin, $100 \mu \mathrm{g} / \mathrm{ml}$ streptomycin, $10 \% \mathrm{FCS}, 5 \mathrm{mM}$ EDTA for $60 \mathrm{~min}$ at $37^{\circ} \mathrm{C}$. The tissues were then digested with collagenase D $(400 \mathrm{U} / \mathrm{ml}$; Boehringer Mannheim GmbH, Mannheim, Germany) in RPMI- 1640 containing $10 \% \mathrm{FCS}$ for $30 \mathrm{~min}$ at $37^{\circ} \mathrm{C}$ and further incubated in the presence of $5 \mathrm{mM}$ EDTA for 5 $\mathrm{min}$. The isolated cells were purified by centrifugation through a $14.5 \%$ Accudenz gradient (Accurate Chemical \& Scientific Corp., Westbury, New York, USA). Cells were further incubated with mouse CD11c microbeads (Miltenyi Biotech, Bergisch Gladbach, Germany) and selected on autoMACS separation columns (Miltenyi Biotech). The purified dendritic cell fractions were more than $95 \%$ CD $11 c^{+}$. These cells $\left(10^{5}\right)$ were seeded on 96-well plate and cultured in the presence or absence of 
$100 \mathrm{ng} / \mathrm{ml}$ LPS for $24 \mathrm{~h}$. Concentrations of IL-6 and IL-12 in the culture supernatants were analyzed by ELISA. Cytokine production by splenic and colonic $\mathrm{CD}^{+} \mathrm{T}$ cells. Spleens were removed aseptically and single-cell suspensions were prepared. After the lysis of red blood cells, cells were incubated with CD4 microbeads and passed through a magnetized column (Miltenyi Biotech). The purified $\mathrm{T}$ cell fractions were more than 95\% $\mathrm{CD}^{+}$and more than $99 \%$ viable. Lymphocytes of the lamina propria of the large intestine were isolated as previously described (26). In brief, after excision of colonic patches, the intestinal tissues were treated with RPMI-1640 medium containing 1 mM EDTA for 20 min to remove the epithelial cells. The tissue was then digested with $0.5 \mathrm{mg} / \mathrm{ml}$ of collagenase $(400 \mathrm{U} / \mathrm{ml}$; Boehringer Mannheim $\mathrm{GmbH}$ ) for $20 \mathrm{~min}$ at $37^{\circ} \mathrm{C}$, and this step was repeated two times. The collected cells were washed and filtered through a nylon mesh. $\mathrm{CD}^{+} \mathrm{T}$ cells were purified by the magnetic activated cell-sorter system (Miltenyi Biotech) as described above. $\mathrm{CD}^{+} \mathrm{T}$ cells were seeded on anti-CD3 Ab-coated (10 $\mu \mathrm{g} / \mathrm{ml}$ in PBS) 96-well plates and cultured for $24 \mathrm{~h}$. Concentrations of IFN- $\gamma$ in the culture supernatants were analyzed by ELISA, according to the manufacturer's directions (Genzyme).

Immunobistochemical analysis. Freshly obtained large intestine was washed with PBS and frozen in Tissue-Tec OCT compound (Sakura, Tokyo, Japan). Cryostat sections $(6 \mu \mathrm{m})$ were fixed with cold acetone for $2 \mathrm{~min}$ and dried and rehydrated with PBS. This step was followed by blocking with PBS containing 20 mM HEPES, 10\% FBS, and $1 \mu \mathrm{g}$ of Fc-blocking mAb (2.4G2; BD PharMingen, San Diego, California, USA). Sections were stained with FITC-conjugated anti-CD11c (HL3; BD PharMingen) and phycoerythrin-conjugated (PE-conjugated) anti-CD3e (145-2C11; BD PharMingen) or PE-conjugated anti-CD11b (M1/70; BD PharMingen) mAbs for $2 \mathrm{~h}$ at room temperature. After washing with PBS, the sections were analyzed by confocal microscopy (BioRad Laboratories Inc., Hercules, California, USA).
For IL-12 staining, tyramide signal amplification method was adopted (TSA Biotin System; NEN Life Science Products Inc., Boston, Massachusetts, USA). Briefly, fixed cryostat sections were incubated with biotin-conjugated IL-12 (p40/p70) mAb (C17.8; BD PharMingen) for $1 \mathrm{~h}$ at room temperature, and washed with washing buffer. Then, sections were stained with streptavidin-HRP and biotinyl tyramide amplification reagent. The sections were then incubated with streptavidin-PE (BD PharMingen) and FITC-conjugated anti-CD11c (HL3; BD PharMingen) or FITC-conjugated anti-CD11b (M1/70; BD PharMingen).

Northern blot analysis. Peritoneal macrophages were treated with LPS for $2 \mathrm{~h}$. Total RNA $(10 \mu \mathrm{g})$ was extracted using the TRIzol reagent (Invitrogen Corp., San Diego, California, USA), electrophoresed, transferred to a nylon membrane, and hybridized with cDNA probe specific for SOCS3, IL-12p40, and $\beta$-actin.

\section{Results}

Stat1/Stat3 double-mutant mice developed chronic colitis. In macrophages from myeloid-specific Stat3 mutant mice, Stat 1 is constitutively phosphorylated (20). Stat 1 has been shown to be essential for signaling mediated by IFN- $\gamma$, which is known to be an important cytokine for the priming of macrophage activity (21). Therefore, we expected the constitutive activation of Stat 1 to confer abnormal activity of Stat 3 mutant macrophages. To address this issue, we generated mice lacking both Stat 1 and Stat3.

We performed a histopathological analysis on colons of 8-week-old Stat1/Stat3 double-mutant mice (Figure $1, a-d)$. Control and Stat 1 mutant mice did not show any sign of pathological changes. On the contrary, the colonic wall of Stat $1 /$ Stat 3 double-mutant mice was thickened, and the gland number was severely reduced, as is the case in Stat 3 mutant mice. These histopathological changes were observed as early as 5-6 weeks of age in both Stat 3 mutant and Stat $1 /$ Stat 3 doublemutant mice. Almost all regions of the colon were
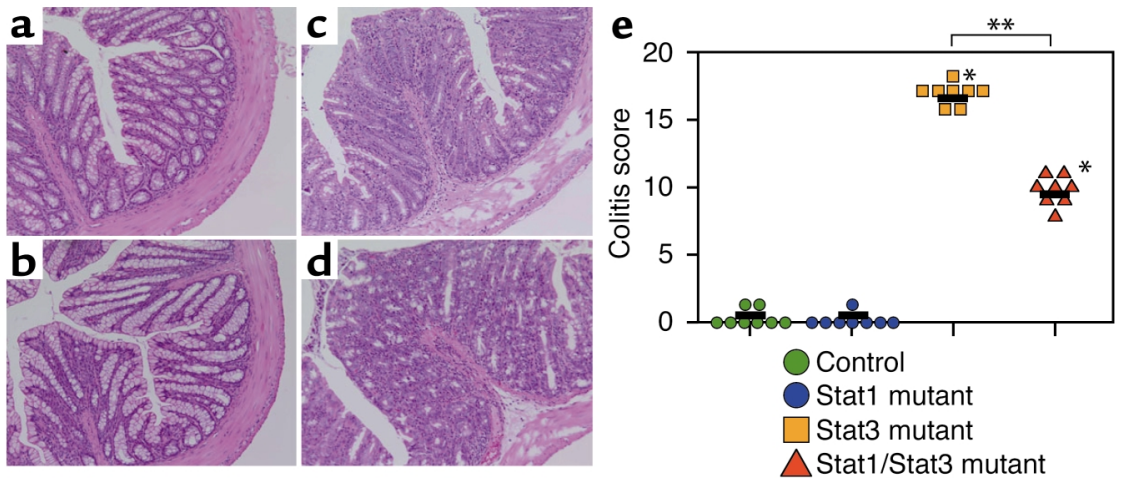

\section{Figure 1}

IBDs in Stat1/Stat3 double-deficient mice. (a-d) Histologic examination of the colons of (a) control, (b) Stat1-deficient, (c) Stat3 mutant, and (d) Stat $1 /$ Stat 3 double-mutant mice at 8 weeks. H\&E staining is shown. $\times 20$. (e)The colitis scores shown for individual mice at 16 weeks of age were total scores for individual sections as described in Methods. The severity of colitis in Stat $1 /$ Stat 3 double-mutant mice was significantly but only partially improved compared with Stat 3 mutant mice $\left({ }^{*} P<0.01\right)$. ${ }^{*} P<0.001$ versus group of control mice. 

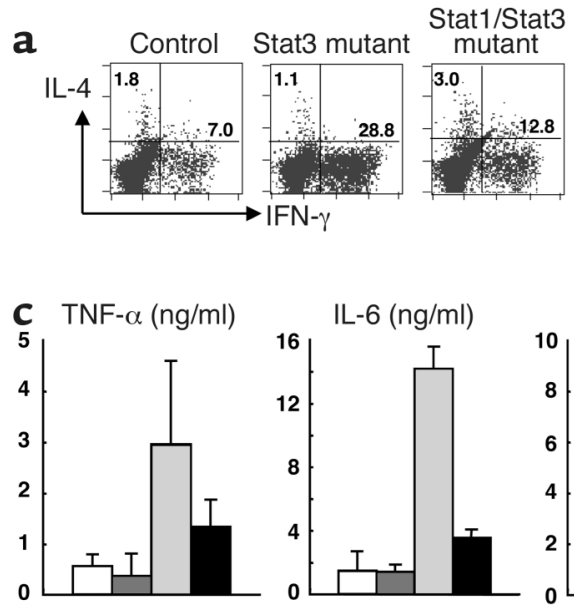

b

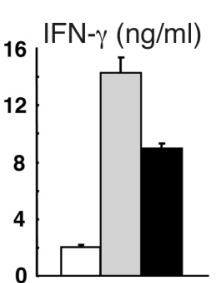

IL-12 (ng/ml)

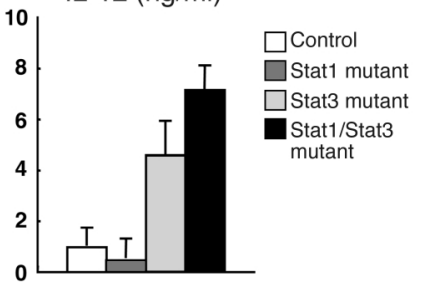

\section{Figure 2}

Enhanced IFN- $\gamma$ production in Stat $1 /$ Stat 3 double-deficient mice. (a) Spleen cells were stimulated with PMA and ionomycin for $6 \mathrm{~h}$, then stained for CD4, fixed, and finally stained for IFN- $\gamma$ and IL-4. Cells were analyzed on FACS by gating on $\mathrm{CD}^{+}$population. The frequency of cytokine-producing $\mathrm{CD} 4^{+}$cells is indicated as a percentage. (b) $\mathrm{CD}^{+} \mathrm{T}$ cells were purified from lamina propria and stimulated with plate-bound anti-CD3 Ab. The concentration of IFN- $\gamma$ was measured by ELISA. (c) Mice were intraperitoneally injected with thioglycollate, and 3 days later peritoneal macrophages were isolated. Macrophages were stimulated with $10 \mathrm{ng} / \mathrm{ml}$ LPS for $24 \mathrm{~h}$. Concentrations of TNF- $\alpha, \mathrm{IL}-6$, and IL-12p40 in the culture supernatants were measured. affected in Stat3 mutant mice, but not in Stat1/Stat3 double-mutant mice at 24 weeks of age. In addition, occurrence of ulcer and abscess was reduced in Stat $1 /$ Stat 3 double-mutant mice compared with Stat3 single-mutant mice. Thus, Stat $1 /$ Stat 3 double-mutant mice developed chronic enterocolitis, although the severity of the colitis was diminished compared with Stat3 mutant mice (Figure 1e).

We next analyzed production of IFN- $\gamma$ by $\mathrm{CD}^{+} \mathrm{T}$ cells isolated from spleens of Stat1/Stat3 doublemutant and Stat 3 mutant mice. Splenic T cells were stimulated with PMA and ionomycin, and production of IFN- $\gamma$ and IL- 4 by $\mathrm{CD}^{+}$cells was analyzed by intracellular staining (Figure 2a). IFN- $\gamma$-producing $\mathrm{CD}^{+} \mathrm{T}$ cells were significantly elevated in Stat 3 single-mutant mice. IFN- $\gamma$-producing cells were also increased in Stat $1 /$ Stat 3 double-mutant mice compared with that of control mice, albeit the reduced numbers were in comparison to Stat 3 mutant $\mathrm{T}$ cells. We further purified $\mathrm{CD} 4^{+} \mathrm{T}$ cells from the intestinal lamina propria of these mice and analyzed for IFN- $\gamma$ production by ELISA (Figure $2 \mathrm{~b}$ ). Intestinal $\mathrm{CD} 4^{+} \mathrm{T}$ cells from Stat $1 /$ Stat 3 double-mutant mice produced increased level of IFN- $\gamma$ compared with control $\mathrm{T}$ cells. Thus, these findings demonstrated that double mutation of Stat 1 and Stat3 resulted in the increase of IFN- $\gamma$ production by intestinal $\mathrm{CD} 4^{+} \mathrm{T}$ cells in addition to splenic $\mathrm{CD} 4^{+} \mathrm{T}$ cells, indicating an enhanced $\mathrm{Th} 1$ response.
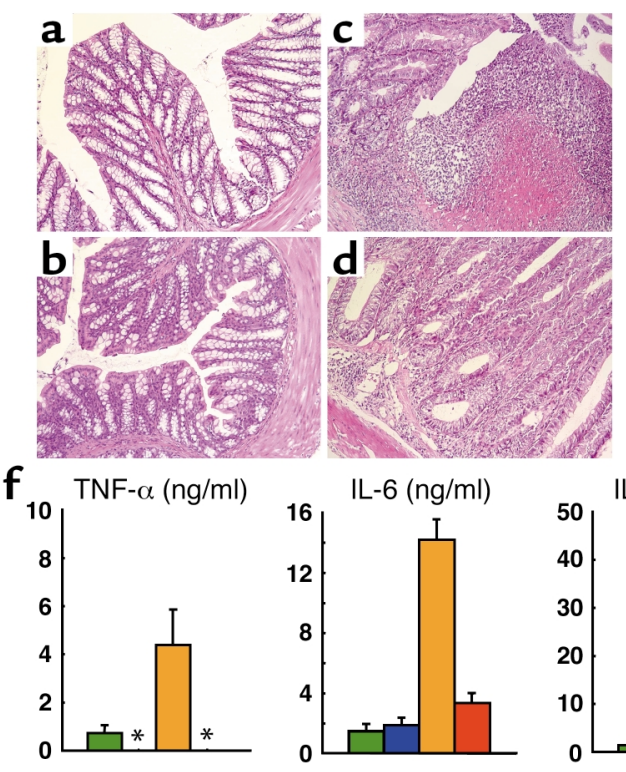

\section{e}
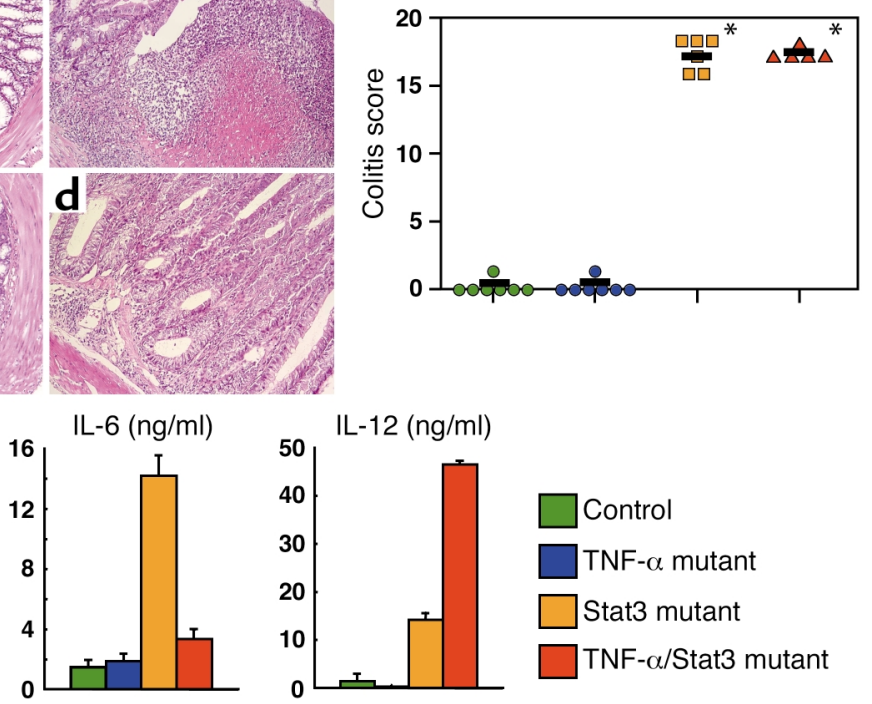

Figure 3

IBDs in TNF- $\alpha /$ Stat3 double-deficient mice. (a-d) Histologic examination of the colons of (a) control, (b) TNF- $\alpha$-deficient, (c) Stat3 mutant, and (d) TNF- $\alpha /$ Stat 3 double-mutant mice at 16 weeks. H\&E staining is shown. $\times 20$. (e) The colitis score of TNF- $\alpha /$ Stat 3 double-mutant mice at 16 weeks of age. TNF- $\alpha /$ Stat 3 double-mutant mice developed severe chronic colitis, similar to Stat 3 mutant mice. ${ }^{*} P<0.001$ versus group of control mice. (f) Mice were intraperitoneally injected with thioglycollate, and 3 days later peritoneal macrophages were isolated. Macrophages were stimulated with $10 \mathrm{ng} / \mathrm{ml}$ LPS for $24 \mathrm{~h}$. Concentrations of TNF- $\alpha$, IL-6, and IL-12p40 in the culture supernatants were measured. ${ }^{*}$ Not detected. 


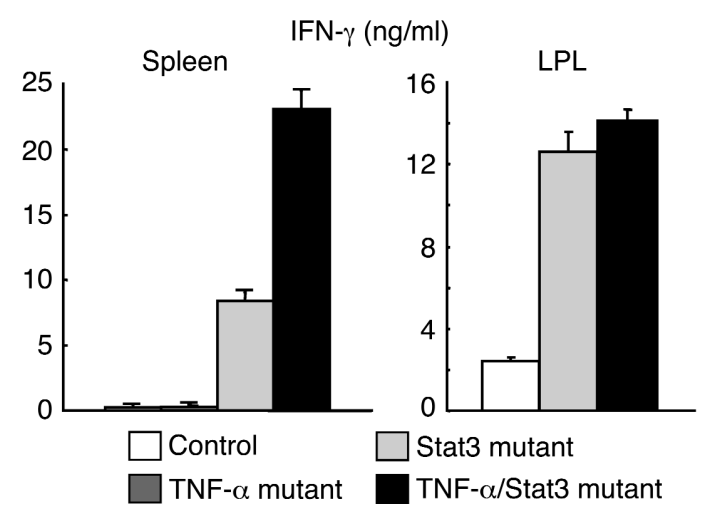

Figure 4

IFN- $\gamma$ production by $\mathrm{CD}^{+} \mathrm{T}$ cells in spleen and lamina propria of TNF- $\alpha /$ Stat 3 double-mutant mice. $C D 4^{+} T$ cells were purified from spleen and lamina propria (LPL), and stimulated with plate-bound anti-CD3 Ab. The concentration of IFN- $\gamma$ was measured by ELISA. $\mathrm{CD} 4^{+} \mathrm{T}$ cells from TNF- $\alpha /$ Stat 3 double-mutant mice produced significantly increased levels of IFN- $\gamma$, similar to Stat 3 mutant mice.

Based on the result obtained by the analysis of $\mathrm{CD}^{+}$ $\mathrm{T}$ cells, our next experiment was to characterize macrophages. Although the analysis of the peritoneal macrophages does not directly reflect involvement of macrophages in intestinal inflammation, the inflammatory response can be estimated in cells of other origins, because the enhanced IFN- $\gamma$ production was observed not only in the intestinal $\mathrm{T}$ cells but also in splenic $\mathrm{T}$ cells (Figure 2, a and $\mathrm{b}$ ). Peritoneal macrophages isolated from Stat $1 /$ Stat 3 double-mutant mice produced increased levels of TNF- $\alpha$ and IL- 6 compared with control or Stat 1 mutant macrophages, albeit lower compared with Stat 3 mutant macrophages (Figure 2 c). IL-12p40 production from Stat $1 /$ Stat 3 double-mutant macrophages was comparable to that of Stat 3 single-mutant macrophages. From these findings we speculated that inflammatory cytokine synthesis contributes to the development of chronic enterocolitis in Stat1/Stat3 double-mutant mice.

TNF- $\alpha /$ Stat 3 double-deficient mice suffered from severe chronic enterocolitis. TNF- $\alpha$ is involved in a variety of inflammatory processes, including the development of IBD (27). Indeed, our previous and present studies demonstrated that the level of TNF- $\alpha$ production was increased in Stat 3 mutant mice (Figure 2c). Therefore, we next generated mice lacking both Stat 3 and TNF- $\alpha$. Surprisingly, inflammatory changes including loss of gland, infiltration by inflammatory cells, crypt abscess, and ulcers were observed in the colon of TNF- $\alpha /$ Stat 3 double-mutant mice. The severity of disease was similar to that of Stat 3 mutant mice (Figure 3,a-e). All of the TNF- $\alpha /$ Stat 3 double-mutant mice analyzed (six mice) developed severe chronic enterocolitis, as did Stat 3 mutant mice (Figure $3 e)$. We next analyzed the LPS-induced inflammatory cytokine production by peritoneal macrophages. TNF- $\alpha /$ Stat 3 double-mutant macrophages produced increased levels of IL-6 and IL-12 compared with macrophages isolated from control mice (Figure $3 \mathrm{f}$ ). In particular, an extremely high level of IL-12p40 was produced by TNF- $\alpha /$ Stat 3 double-mutant macrophages.

In the next set of experiments, production of IFN- $\gamma$ by $\mathrm{CD}^{+} \mathrm{T}$ cells isolated from spleen or intestinal lamina propria of TNF- $\alpha /$ Stat 3 double-mutant mice with colitis was analyzed (Figure 4). $\mathrm{CD} 4^{+} \mathrm{T}$ cells isolated from both spleen and intestinal lamina propria of TNF- $\alpha$ / Stat3 double-mutant mice as well as Stat 3 singlemutant mice produced increased levels of IFN- $\gamma$. Thus, TNF- $\alpha /$ Stat 3 double-mutant mice also showed skewed Th1 responses and developed chronic enterocolitis.

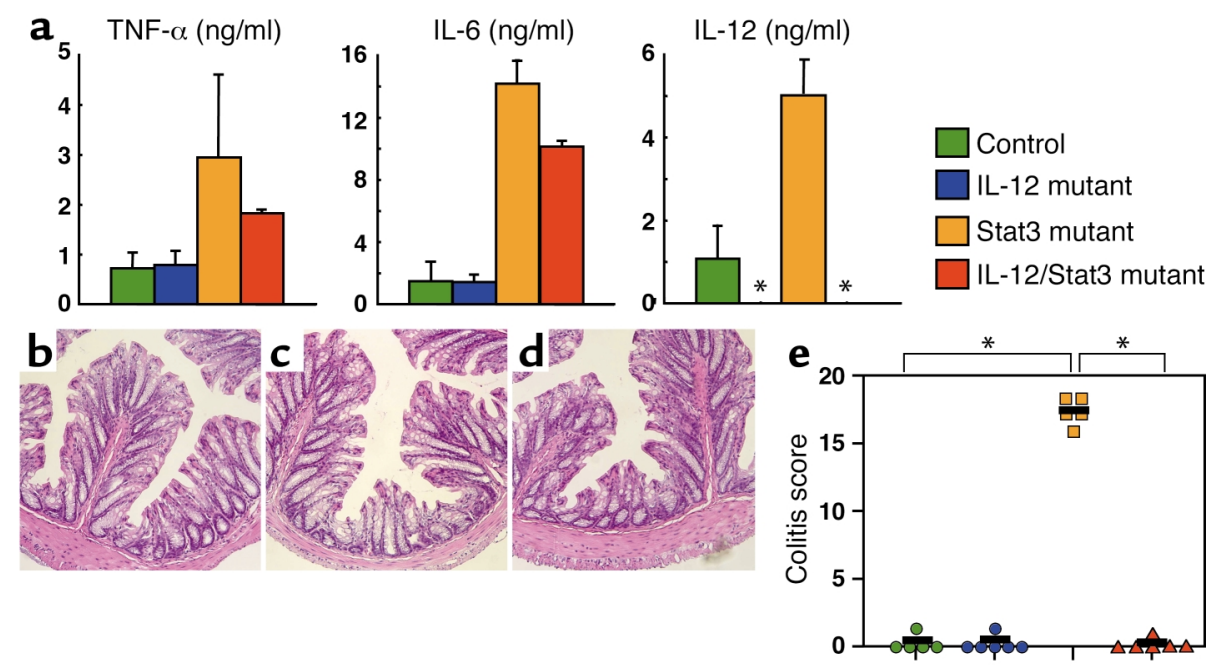

\section{Figure 5}

IL-12/Stat3 double-mutant mice showed no inflammatory change in the colon. (a) Peritoneal macrophages were stimulated with $10 \mathrm{ng} / \mathrm{ml}$ LPS for $24 \mathrm{~h}$. Concentrations of TNF- $\alpha$, IL-6, and IL-12p40 in the culture supernatants were measured. *Not detected. (b-d) Histopathology of the colons of (b) control, (c) IL-12-deficient, and (d) IL-12/Stat3 double-mutant mice at 16 weeks. H\&E staining is shown. $\times 20$. (e) The colitis score of IL-12/Stat3 double-mutant mice at 16 weeks of age. None of the IL-12/Stat3 double-mutant mice showed any inflammatory change in the colon. ${ }^{*} P<0.001$ between Stat 3 mutant mice and control or IL-12/Stat3 double-mutant mice. 


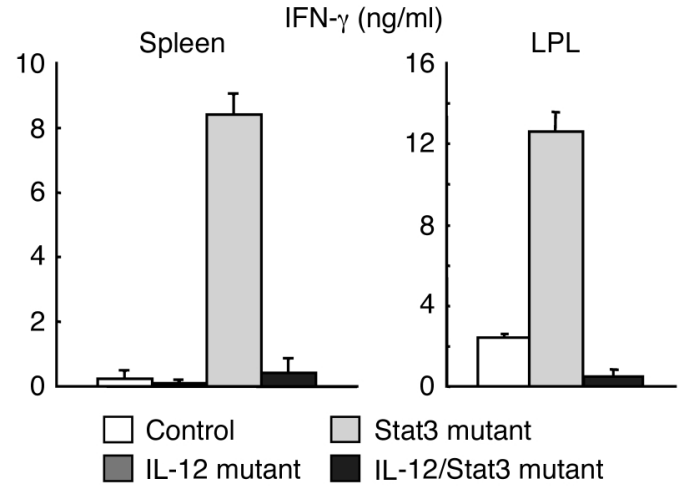

Figure 6

Normal production of IFN- $\gamma$ by $\mathrm{CD}^{+}{ }^{+} \mathrm{T}$ cells in spleen and lamina propria of IL-12/Stat3 double-mutant mice. $\mathrm{CD} 4^{+} \mathrm{T}$ cells were purified from spleen and lamina propria (LPL) and stimulated with platebound anti-CD3 Ab. The concentration of IFN $-\gamma$ was measured by ELISA. CD4 ${ }^{+} T$ cells from IL-12/Stat 3 double-mutant mice produced normal levels of IFN- $\gamma$, unlike those from Stat 3 mutant mice.

IL-12p40/Stat3 double-mutant mice did not develop chronic enterocolitis. Based on the data obtained by the analysis of Stat 3 mutant mice inserted with additional gene manipulation (Figures 1-3), it was obvious that elevated IL-12p40 synthesis by macrophages was consistently associated with the colitis development. Thus, it was logical to generate IL-12p40/Stat3 double-mutant mice. The analysis of the LPS-induced production of inflammatory cytokines by peritoneal macrophages revealed that IL-12p40/Stat3 double-mutant macrophages produced increased levels of TNF- $\alpha$ and IL- 6 , which was comparable to those of Stat 3 mutant macrophages (Figure 5a). The double-mutant mice, however, did not show any pathological sign of inflammation in the colon (Figure 5, b-e). They also did not develop colitis even at over 24 weeks of age, when Stat 3 mutant mice suffered from severe chronic enterocolitis (data not shown). These findings suggested a critical role of IL-12p40 for the development of colitis associated with Stat 3 deficiency.

To further support this view, we next analyzed the production of IFN- $\gamma$ by $\mathrm{CD}^{+} \mathrm{T}$ cells isolated from spleen and colonic lamina propria of the doublemutant mice (Figure 6). Colonic lamina propria CD4 ${ }^{+}$ $\mathrm{T}$ cells of Stat 3 mutant mice showed increased production of IFN- $\gamma$; however, IFN- $\gamma$ production by colonic lamina propria $\mathrm{CD}^{+}{ }^{+} \mathrm{T}$ cells of IL-12p40/Stat3 doublemutant mice was reduced to the level of control mice. Similar results were obtained when splenic $\mathrm{CD}^{+} \mathrm{T}$ cells were examined (Figure 6). Taken together, these results demonstrated that IL-12p40/Stat3 double-mutant mice did not develop chronic enterocolitis with no pathological IFN- $\gamma$ producing Th1-type responses. We thus suggest that IL-12-induced development of Th1 cells leads to the induction of severe chronic enterocolitis in Stat 3 mutant mice.

RAG2/Stat3 double-mutant mice did not develop chronic enterocolitis. To further confirm the critical role of Th1 cells in the development of chronic enterocolitis in Stat 3 mutant mice, we next generated RAG2/Stat 3 double-mutant mice, which lack $\mathrm{T}$ cells. Similar to macrophages obtained from Stat 3 mutant mice, macrophages isolated from these double-mutant mice produced increased levels of inflammatory cytokines such as TNF- $\alpha$, IL-6, and IL-12p40 (Figure 7a). RAG2/ Stat3 double-mutant mice, however, did not show any inflammatory change in the colon (Figure 7, b-e).
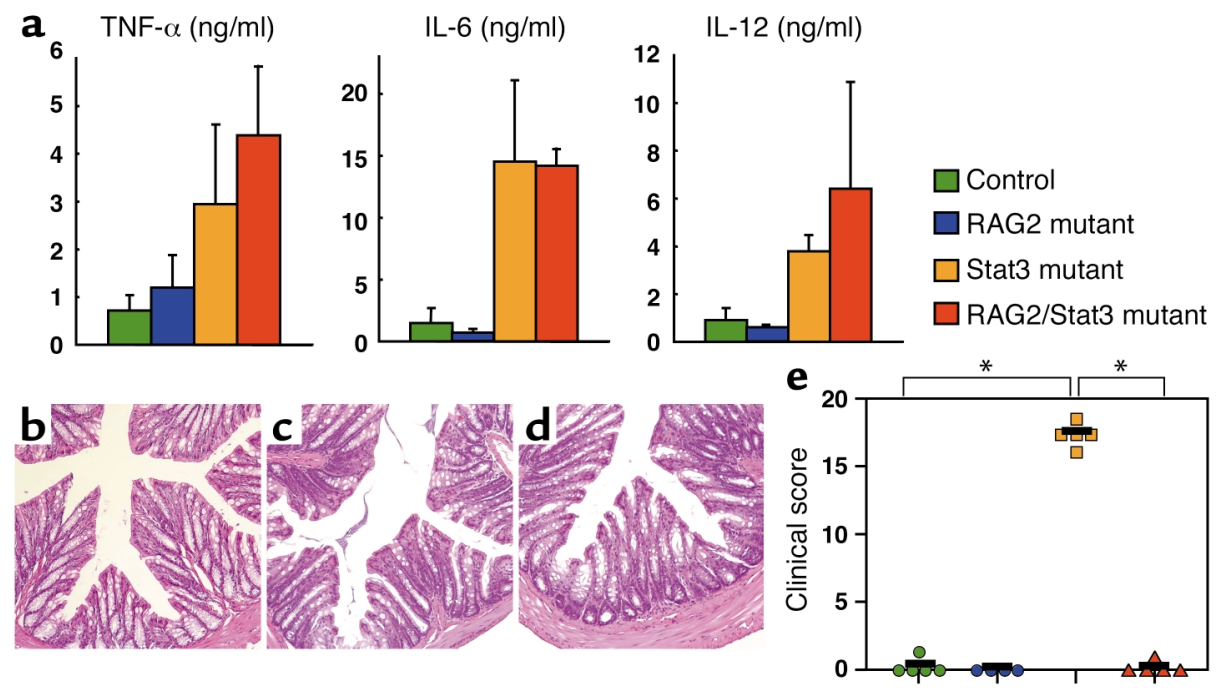

Figure 7

RAG2/Stat3 double-mutant mice showed no inflammatory change in the colon. (a) Peritoneal macrophages were stimulated with $10 \mathrm{ng} / \mathrm{ml}$ LPS for $24 \mathrm{~h}$. Concentrations of TNF- $\alpha$, IL-6, and IL-12p40 in the culture supernatants were measured. (b-d) Histopathology of the colon of (b) control, (c) RAG2-deficient, and (d) RAG2/Stat3 double-mutant mice at 16 weeks. H\&E staining is shown. $\times 20$. (e) The colitis score of RAG2/Stat3 double-mutant mice at 16 weeks of age. None of the RAG2/Stat3 double-mutant mice showed any inflammatory change in the colon. ${ }^{*} P<0.001$ between Stat 3 mutant mice and control or RAG2/Stat3 double-mutant mice. 


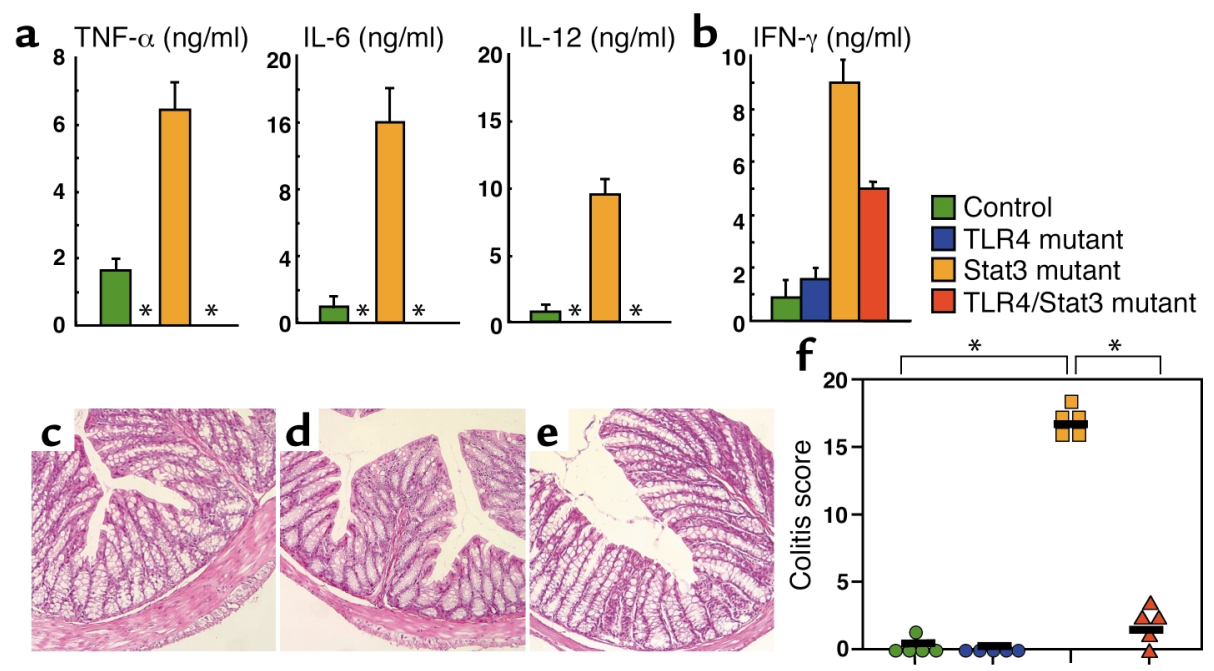

\section{Figure 8}

Improved colitis in TLR4/Stat3 double-mutant mice. (a) Peritoneal macrophages were stimulated with $10 \mathrm{ng} / \mathrm{ml}$ LPS for 24 h. Concentrations of TNF- $\alpha$, IL-6, and IL-12p40 in the culture supernatants were measured. LPS-induced production of inflammatory cytokines was abolished in TLR4/Stat3 double-mutant macrophages. ${ }^{*}$ Not detected. (b) CD4 ${ }^{+} T$ cells were purified from spleen and stimulated with platebound anti-CD3 Ab. The concentration of IFN- $\gamma$ was measured by ELISA. CD4 ${ }^{+} T$ cells from TLR4/Stat 3 double-mutant mice produced reduced levels of IFN- $\gamma$ compared with Stat3 mutant mice. (c-e) Histopathology of the colon of (c) control, (d) TLR4-deficient, and (e) TLR4/Stat3 double-mutant mice at 16 weeks. H\&E staining is shown. $\times 20$. (f) The colitis score of TLR4/Stat 3 double-mutant mice at 16 weeks of age. TLR4/Stat 3 double-mutant mice showed no or moderate inflammatory changes in the colon. ${ }^{*} P<0.001$ between Stat 3 mutant mice and control or TLR4/Stat3 double-mutant mice.

None of the double-mutant mice analyzed developed chronic enterocolitis even after 24 weeks of age (data not shown). These findings further support our hypothesis that myeloid cell-originated IL-12p40 mediates the induction of Th1 cells contributing to the development of chronic enterocolitis in Stat 3 mutant mice.

TLR4 is involved in the pathogenesis of colitis in Stat 3 mutant mice. In the absence of Stat3, macrophages were abnormally activated and produced increased levels of inflammatory cytokines such as IL-12p40 (Figures 2, 3, $5,7)$. It was thus important to elucidate the triggering mechanism for the increased production of IL-12p40 by Stat 3 mutant macrophages. The biosynthesis of inflammatory cytokines including IL-12p40 is known to be induced by stimulation with bacterial components such as LPS (28). Bacterial components have recently been shown to be specifically recognized by the pattern recognition family of TLRs (29). Among the family members, TLR4 is an essential receptor for the recognition of LPS $(24,30)$. Therefore, we finally generated TLR4/Stat3 double-mutant mice and analyzed

\section{Figure 9}

Impaired IL-10-induced expression of SOCS3 in Stat3 mutant macrophages. (a) Peritoneal macrophages from control and Stat 3 mutant mice were stimulated with $10 \mathrm{ng} / \mathrm{ml} \mathrm{IL-10}$ for $2 \mathrm{~h}$ and analyzed for SOCS3 mRNA expression by Northern blotting. (b) Peritoneal macrophages from control and Stat 3 mutant mice were cultured in the presence or absence of $10 \mathrm{ng} / \mathrm{ml} \mathrm{IL-10}$ for $24 \mathrm{~h}$ and then stimulated with $10 \mathrm{ng} / \mathrm{ml}$ LPS for $2 \mathrm{~h}$. Total RNA was extracted and subjected to Northern blot analysis for IL-12p40 mRNA expression. The same membrane was rehybridized with $\beta$-actin. whether TLR4 is involved in the abnormal activation of Stat 3 mutant macrophages leading to the pathological Th1 cell-mediated large intestinal inflammation. As one might expect, LPS-induced production of inflammatory cytokines was not observed at all in macrophages isolated from TLR4/Stat3 double-mutant mice (Figure 8a). We further analyzed the production of IFN- $\gamma$ by $C D 4^{+} T$ cells of TLR4/Stat 3 double-mutant mice (Figure $8 \mathrm{~b}$ ). The level of IFN- $\gamma$ production by $\mathrm{CD}^{+}{ }^{+} \mathrm{T}$ cells isolated from TLR $4 /$ Stat 3 double-mutant mice was significantly decreased compared with Stat3 mutant mice. Thus, aberrant production of an inflammatory initiator cytokine, IL-12, by myeloid cells and

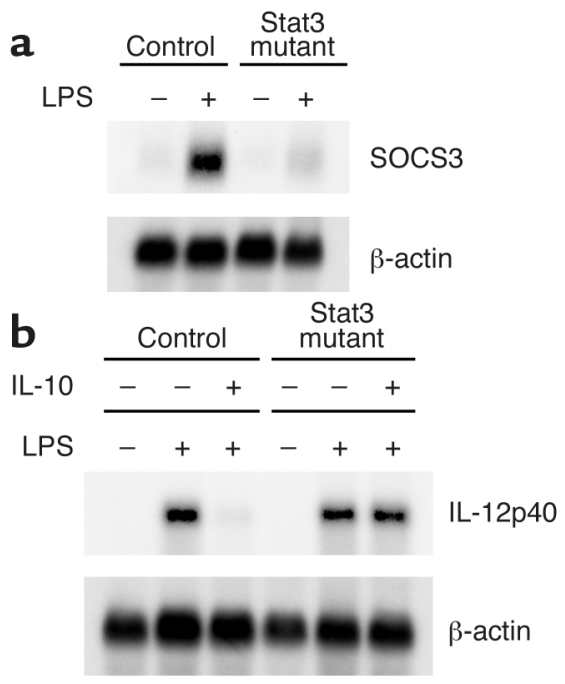



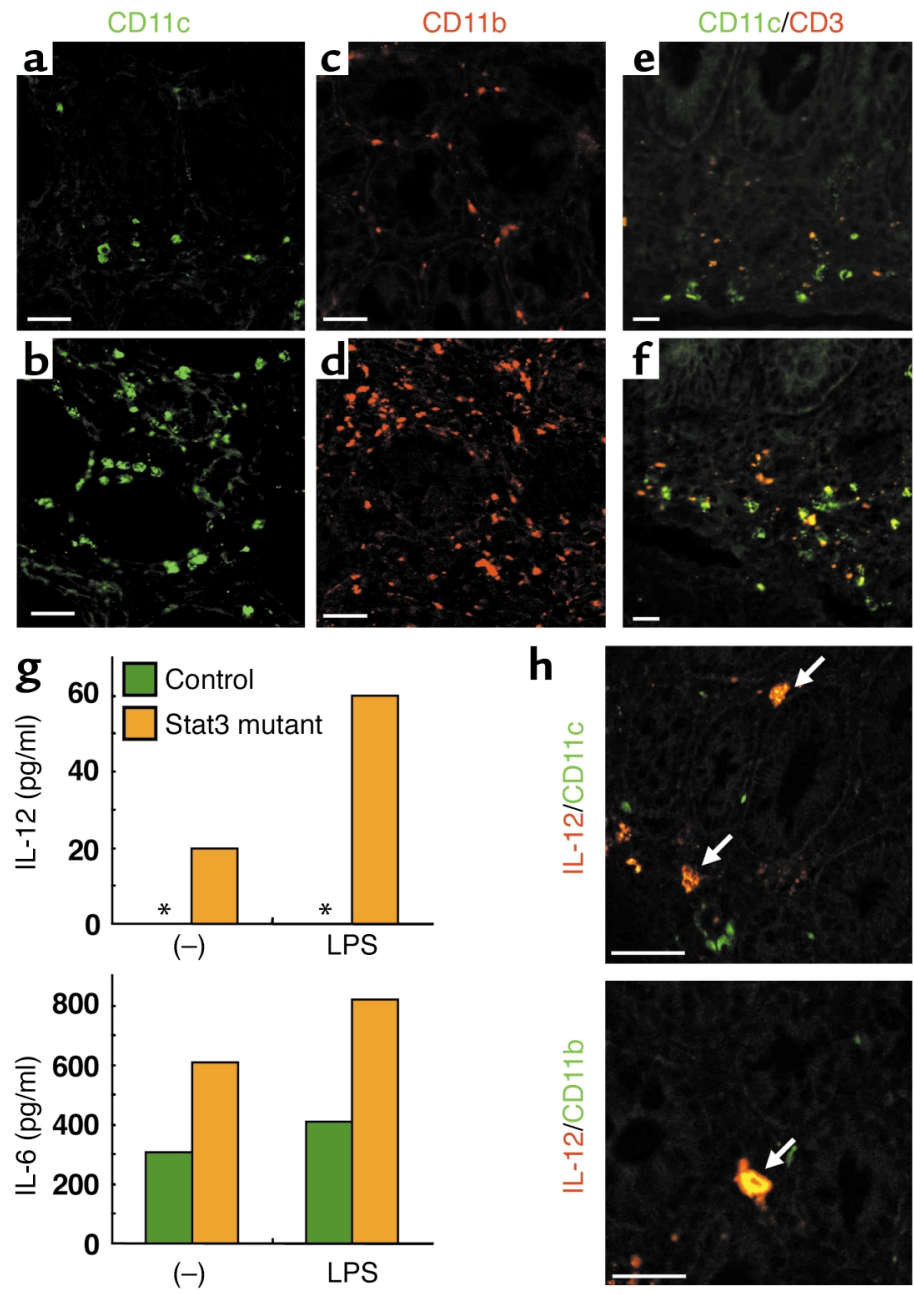

Control

Stat3

mutant

\section{Figure 10}

Macrophages and dendritic cells in the large intestine were increased in number and produced IL-12p40 in Stat 3 mutant mice with colitis. (a-f) Immunohistochemistry of the colon of $(\mathbf{a}, \mathbf{c}, \mathbf{e})$ control and $(\mathbf{b}, \mathbf{d}$, f) Stat 3 mutant mice at 16 weeks. The colon sections were stained with anti-CD11c Ab (green) $(\mathbf{a}, \mathbf{b}, \mathbf{e}, \mathbf{f})$, anti-CD11b Ab (red) (c and d), and anti-CD3 Ab (red) (e and f). Bar: $10 \mu \mathrm{m}$. (g) CD11c-positive dendritic cells in the large intestine were stimulated with $100 \mathrm{ng} / \mathrm{ml}$ LPS for $24 \mathrm{~h}$. Concentrations of IL- 6 and IL-12p40 in the culture supernatants were measured. * Not detected. (h) Immunohistochemistry of the colon of Stat 3 mutant mice. The colon sections were stained with anti-IL-12p40 Ab (red) and anti-CD11c $\mathrm{Ab}$ (green) oranti-CD11b Ab (green). Bar: $10 \mu \mathrm{m}$. the Th1 cell development were improved in the absence of TLR4. This notion was further supported by the analysis of the histopathological change in the colon of TLR4/Stat3 double-mutant mice (Figure 8, c-e). At 16 weeks of age, the inflammatory change was scarcely detected in the colon of TLR4/Stat3 double-mutant mice (Figure 8f). These findings clearly demonstrated that removal of the initiation signal by LPS by TLR 4 inhibited the abnormal activation of Stat 3 mutant macrophages, causing the development of colitis. It is important to note, however, that some TLR4/Stat3 double-mutant mice (three of six mice analyzed) showed some signs of inflammatory change in the colon at around 24 weeks of age, although the severity of affected region was reduced compared with Stat3 mutant mice (data not shown). Thus, in the absence of TLR4, the onset of chronic enterocolitis was delayed, and the severity and incidence of colitis was improved. Taken together, these findings indicate that TLR4 is involved in an initiation step of abnormal activation of myeloid cells leading to the development of chronic enterocolitis in Stat 3 mutant mice.

Reduced expression of SOCS3 in Stat 3 mutant macrophages. Findings obtained by analysis of TLR4/Stat3 doublemutant mice suggest that IL-10 exerts an anti-inflam- matory activity by suppressing LPS responsiveness in myeloid cells. Recently, genes induced by IL-10 stimulation in macrophages have been identified and characterized $(31,32)$. Among these gene products, SOCS3 has been shown to inhibit the LPS-induced expression of TNF- $\alpha$, IL-6, and iNOS in macrophages (32). We therefore analyzed IL-10-induced mRNA expression of SOCS3 in peritoneal macrophages of Stat 3 mutant mice (Figure 9a). In control mice, IL-10 stimulation resulted in robust expression of SOCS3 mRNA. IL-10-induced SOCS3 expression, however, was not observed in Stat3 mutant mice. Accordingly, IL-10-mediated suppression of LPS-induced IL-12p40 expression, which was observed in control macrophages, was abrogated in Stat 3 mutant macrophages (Figure 9b). These findings indicate that IL-10-induced activation of Stat 3 is critical to suppression of LPS-induced IL-12p40 production in macrophages, possibly through expression of antiinflammatory molecules such as SOCS3.

Dendritic cells and macrophages in the large intestine were increased in number and showed enhanced IL-12 production in Stat 3 mutant mice. The inflammatory change observed in Stat 3 mutant mice was restricted to the large intestine. Furthermore, our present findings described above provided strong evidence that aberrant production of 
IL-12p 40 by Stat 3 mutant myeloid cells directly contribute to the development of colonic inflammation by the generation of pathological Th1 cell environment. Therefore, we speculate that myeloid cells residing in the large intestine play important roles in the development of colitis in the mutant mice. To directly examine the involvement of mucosal dendritic cells and macrophages in the pathogenesis, immunohistochemical study was carried out in the large intestine of Stat3 mutant mice with colitis. The number of accumulated CD11 $\mathrm{c}^{+}$dendritic cells and CD11 $\mathrm{b}^{+}$macrophages was significantly increased in the large intestine of Stat3 mutant mice compared with those of control mice (Figure 10, a-d). Dendritic cells were mainly observed in the epithelium region and some in the lamina propria and the submucosal regions (Figure 10, a and b). CD11 $\mathrm{b}^{+}$ macrophages were also observed in the epithelium and lamina propria region of the large intestine. Colocalization of $\mathrm{CD}^{+} \mathrm{T}$ cells with $\mathrm{CD} 11 \mathrm{c}^{+}$dendritic cells was rare in the lamina propria of control mice (Figure 10e). Large numbers of $\mathrm{CD}^{+} \mathrm{T}$ cells, however, were located adjacent to $\mathrm{CD} 11 \mathrm{c}^{+}$dendritic cells in Stat 3 mutant mice (Figure 10f). These findings suggest a possibility that localized direct interaction between dendritic cells and $\mathrm{T}$ cells at the mucosal surface may initiate the creation of IL-12mediated pathological Th1 environment leading to the development of colitis.

To examine this possibility, we next purified CD $11 \mathrm{c}^{+}$ dendritic cells from the large intestine of Stat 3 mutant mice for the analysis of cytokine production (Figure $10 \mathrm{~g})$. Dendritic cells isolated from control mice did not show any production of IL-12p40 upon stimulation with LPS. In contrast, dendritic cells obtained from Stat 3 mutant mice showed marked production of IL-12p40 without stimulation (Figure 10g). The level of IL-12p 40 production was further enhanced when cultured with LPS. These findings clearly demonstrated that Stat 3 mutant dendritic cells are committed for the pathological production of IL-12p40. In addition to the elevated IL-12p 40 production, Stat 3 mutant dendritic cells produced increased level of IL- 6 compared with the cells isolated from control mice, although mucosal dendritic cells did not produce any detectable level of TNF- $\alpha$ in both control and Stat 3 mutant mice (Figure 10g, data not shown).

Finally, we examined expression of IL-12 in intestinal macrophages and dendritic cells by immunohistochemistry. In control mice, $\mathrm{CD} 11 \mathrm{~b}^{+}$macrophages and CD $11 \mathrm{c}^{+}$dendritic cells scarcely expressed IL-12 (data not shown). In contrast, both $\mathrm{CD} 11 \mathrm{~b}^{+}$macrophages and CD11 $\mathrm{c}^{+}$dendritic cells expressed IL-12 in the large intestine of Stat 3 mutant mice (Figure 10h). Thus, macrophages and dendritic cells residing in the large intestine were increased in number, showed enhanced production of IL-12, and many of the dendritic cells colocalized with $\mathrm{CD}^{+} \mathrm{T}$ cells. These findings suggest that macrophages and dendritic cells residing in the large intestine are involved in the development of chronic enterocolitis by instruction of Th1 cell development through IL-12p40 production in Stat 3 mutant mice.

\section{Discussion}

In the present study, we analyzed the molecular mechanism by which abnormally activated Stat 3 mutant myeloid cells induce development of chronic enterocolitis in vivo using several gene-manipulated mice where additional gene deletion were introduced into Stat 3 mutant mice. Previous study indicated that IL-10 is an important cytokine that prevents the development of chronic enterocolitis (2). CD4 ${ }^{+} \mathrm{T}$ cells of IL-10-deficient mice showed the Th1 phenotype by producing an increased level of IFN- $\gamma(8)$, and the adoptive transfer of these $\mathrm{CD}^{+} \mathrm{T}$ cells into immunocompromised mice resulted in the induction of colitis (9). Treatment with neutralizing anti-IL-12 Ab prevented the colitis development in young IL-10-deficient mice (10). These lines of evidence indicate that the enterocolitis observed in IL-10-deficient mice is associated with the increased Th1-type responses. It remains unclear, however, how the IL-10 deficiency led to the development of chronic enterocolitis in vivo. This study demonstrated that defective IL-10 signaling caused by the absence of Stat 3 in myeloid cells resulted in the Th1-mediated enterocolitis in mice. Furthermore, aberrant production of IL-12p40 by Stat 3 mutant myeloid cells is a key pathological element for the development of Th1-dependent enterocolitis. In the absence of IL-10 or IL-10 signaling represented by IL-10 knockout or Stat3 deficiency, respectively, myeloid cells including macrophages and dendritic cells were activated and produced increased levels of inflammatory cytokines. Among these inflammatory cytokines, IL-12 instructs the development of Th1 cells, which confer the pathogenesis of enterocolitis. IL-12p40 associates with p35 to form bioactive IL-12 and additionally engages $\mathrm{p} 19$ to form IL-23, which has several overlapping activities with IL-12 (33). Since IL-12p40deficient mice, which lack both IL-12 and IL-23, were used in this study, we cannot exclude a possible pathological role of IL-23 in addition to IL-12 for the development of Th1-dependent diseases.

IL-10 has been shown to instruct the development of regulatory $\mathrm{T}$ cells, which have a capacity to prevent the development of chronic enterocolitis induced by Th1type responses $(12,13)$. In the Stat 3 mutant mice, LPSinduced IL-10 production was significantly increased (20). Furthermore, a population of $\mathrm{CD} 4{ }^{+} \mathrm{CD} 25^{+}$regulatory $\mathrm{T}$ cells in the spleen of the Stat 3 mutant mice was increased compared with control mice (14-17\% versus 5-6\%; our unpublished data). These regulatory $\mathrm{T}$ cells had a low capacity to proliferate and furthermore had an ability to inhibit proliferation of $\mathrm{CD} 4^{+} \mathrm{T}$ cells, indicating that the cells of Stat 3 mutant mice have a normal inhibitory activity as regulatory $\mathrm{T}$ cells (our unpublished data). In the Stat 3 mutant mice, IL-10-mediated signaling was not affected in T cells, because Stat 3 protein was normally observed in the $\mathrm{T}$ cell population (20). 
IL-10 has been shown to induce the development of regulatory $\mathrm{T}$ cells (34). Therefore, overproduction of IL-10 may account for the increased number of regulatory $\mathrm{T}$ cells in the Stat 3 mutant mice. Although regulatory $\mathrm{T}$ cells have been well established to inhibit the development of colitis $(12,13)$, our present and ongoing studies suggest that colitis is developed in the Stat3 mutant mice, despite regulatory $\mathrm{T}$ cells increasingly present. These findings imply that even in the presence of IL-10 and regulatory T cells, exaggerated Th1 responses due to the aberrant activation of myeloid cells lead to the development of chronic inflammation in the Stat 3 mutant mice.

In the Stat 3 mutant mice, there is a possibility that not only Th1 cells but also inflammatory cytokines contribute to the pathogenesis of enterocolitis. In particular, TNF- $\alpha$ is known to be a potent inducer of several inflammatory diseases (27). Indeed, anti-TNF- $\alpha$ $\mathrm{Ab}$ has been used successfully in a clinical setting for the treatment of IBD such as Crohn disease (35). Mice that overproduced TNF- $\alpha$ due to a deletion of adenosine-uracil-rich elements from the $3^{\prime}$-untranslated region of the TNF- $\alpha$ gene developed Crohn-like colitis (36). In this model, colitis was not induced in the RAG1-- background, indicating that lymphocytes are critical mediators for the development of colitis. Additionally, Crohn disease patients who responded to anti-TNF- $\alpha$ Ab showed downregulation of TNF- $\alpha$, and subsequently IFN- $\gamma$, indicating that increased Th1 responses evoked by TNF- $\alpha$ in the mucosa are critical for pathogenesis $(37,38)$. TNF- $\alpha /$ Stat 3 double-mutant mice developed severe chronic enterocolitis (Figure 3). Similarly, treatment with anti-TNF- $\alpha \mathrm{Ab}$ in young IL-10-deficient mice did not prevent colitis (39). Although a report showed that colitis was improved in TNF- $\alpha /$ IL-10 double-deficient mice, some of these mice developed severe colitis (40). Thus, TNF- $\alpha$ does not seem to be directly involved in the pathogenesis of colitis in Stat3 mutant and IL-10-deficient mice. Furthermore, reconstitution of RAG2-deficient mice with $\mathrm{CD}^{+} \mathrm{T}$ cells from Stat 3 mutant mice induced the development of chronic enterocolitis (our unpublished data). Therefore, we conclude that Th1 cells are the most important inducers of chronic enterocolitis in Stat 3 mutant mice. This model clearly demonstrated that abnormal activity by myeloid cells is a first trigger to induce Th1-dependent inflammatory diseases. In TNF- $\alpha /$ Stat 3 double-mutant mice, IL- 12 p 40 production was significantly increased even when compared with Stat 3 single-mutant mice (Figure 3f). TNF- $\alpha$ has been shown to be one of important cytokines that are involved in prevention of microbial infection $(41,42)$. In the apical surface of the large intestine of TNF- $\alpha$ / Stat 3 double-mutant mice, many of rod-type bacteria can be easily detected in comparison with Stat 3 singlemutant and control mice (our unpublished data). Therefore, although precise mechanism by which IL-12p40 production was increased is unclear, we could provide a speculation that the deficiency of TNF- $\alpha$ may lead to the impairment of mucosal innate immunity for the control of intestinal microflola, including the invasion of pathogen via the epithelium. Thus, several intestinal pathogens or commensal bacteria may easily invade into the intestinal tissues, which may result in an increased chronic stimulation of myeloid cell leading to the overproduction of IL-12p 40 .

Although Stat 1 was constitutively activated in Stat3 mutant macrophages by unknown mechanisms (20), the insertion of Stat 1 deficiency only partially improved the severity of colitis in Stat3 mutant mice (Figure 1). Stat 1 plays an essential role in the signaling pathway of IFN- $\gamma$, which is an important mediator of Th1 responses (21). Therefore, Th1-mediated responses should be impaired in Stat $1 /$ Stat 3 double-deficient mice, and thus lack of the disease development was expected. Our findings, however, demonstrated that the insertion of Stat 1 deficiency into Stat 3 mutant mice did not prevent the development of chronic enterocolitis. For the explanation of this unexpected result, we propose two possibilities. One is as follows: several recent reports demonstrated the presence of a Stat1-independent pathway in IFN- $\gamma$ signaling (43-46). In Stat $1 /$ Stat 3 double-deficient mice, IFN- $\gamma$ production from $\mathrm{CD} 4^{+} \mathrm{T}$ cells was significantly increased, indicating that these mice exhibited skewed Th1 responses even in the absence of Stat 1 (Figure 2, b and c). Therefore, IFN- $\gamma$-mediated Stat 1 -independent signaling may confer the induction of chronic colitis in these double-mutant mice. Alternatively, the adoptive transfer of $\mathrm{CD} 4^{+} \mathrm{T}$ cells isolated from IFN- $\gamma-$ deficient mice has been shown to induce Th1-mediated colitis in immunocompromised mice (47). Treatment with anti-IFN- $\gamma \mathrm{Ab}$ was less effective than anti-IL-12 Ab in preventing the colitis development in IL-10-deficient mice $(8,10)$. These results indicate that destructive cellmediated immune responses can be provided by Th1 cells without the involvement of IFN- $\gamma$ production for the development of colitis.

In this study, a key initiator molecule that can trigger an abnormal activation of myeloid cells in the absence of IL-10 signaling was also demonstrated. A family of TLRs has recently been identified as pattern recognition molecules of microbial components, which leads to the activation of innate immune cells such as macrophages and dendritic cells (29). Among these TLRs, TLR4 is essential for the recognition of LPS. In the absence of TLR4, macrophages from Stat 3 mutant mice did not produce any inflammatory cytokines in response to LPS, and the incidence and severity of colitis were greatly improved (Figure 8). These findings indicate that TLR4 is a key initiating molecule, which triggers an abnormal activation of myeloid cells leading to the development of chronic enterocolitis. Previous studies showed that various genemanipulated mice developing colitis in a specific pathogen-free environment do not show any inflammatory change in a germ-free environment and that treatment of young IL-10-deficient mice with antibiotics prevented the development of colitis $(48,49)$. These findings indicate that one contributing factor for the 
triggering mucosal inflammation could be "intestinal microflora," commensal microorganisms resident on the mucosal surface (7). Therefore, we propose the following hypothesis: TLRs expressed on myeloid cells recognize microbial components of the mucosal microflora and activate myeloid cells to produce inflammatory cytokines including IL-10, IL-12, and TNF- $\alpha$. In normal conditions, IL-10, which is produced by myeloid cells and regulatory $T$ cells, suppresses the activity of myeloid cells. In the absence of IL-10 signaling, however, myeloid cells are abnormally activated through TLRs and produce increased levels of inflammatory cytokines. Among these, IL-12 induces the development of colitis through the generation of aberrant Th1 cells.

Some of TLR4/Stat3 double-mutant mice developed colitis at old age, indicating that other TLRs may be involved in the initiation of pathogenesis. TLR9, which induces potent Th1 responses through recognition of CPG DNA in vivo, is one such candidate (50). CpG DNA induced increased production of inflammatory cytokines, including IL-12p40, in TLR4/Stat3 doublemutant macrophages (our unpublished data). Therefore, we speculate that constitutive exposure of microbial components such as CPG DNA may eventually prime myeloid cells to produce increased level of inflammatory cytokines in the TLR4/Stat 3 doublemutant mice. Even in the absence of LPS signaling, the abnormal activity of myeloid cells may eventually lead to the induction of pathological Th1 responses in the double-mutant mice. It should be noted, however, that the level of the CPG DNA/TLR9-mediated IL-12p40 production by the double-mutant macrophages was lower when compared with the Stat3 mutant macrophages, which may explain one of the causes for the improvement of colitis in the double-mutant mice (our unpublished data). In addition to TLR9, TLR5, which has been shown to be expressed on the basolateral side of intestinal epithelia and recognize bacterial flagellin, may also be involved in the initiation of inflammation cascade in the large intestine $(51,52)$.

One of the other interesting findings of the present study is the demonstration of the accumulation of dendritic cells and macrophages in the disease site of Stat 3 mutant mice (Figure 10). These myeloid lineages of mucosal APCs produced increased level of inflammatory cytokines such as IL-12p40 and IL-6. It should also be noted that colocalization of mucosal dendritic cells and $\mathrm{CD}^{+} \mathrm{T}$ cells was directly demonstrated in the large intestine of Stat3 mutant mice with colitis. Furthermore, intestinal dendritic cells have been shown to extend their dendron to the lumen side of the intestine (53). Thus, the direct communication between the dendritic cell/T cell clusters and outside environments, including the commensal microflora, may occur through TLRs and microbial components, respectively, at the intestinal mucosa, which instructs the initiation of large-intestinal inflammation in Stat 3 mutant mice.

Finally, we demonstrated that IL-10-induced expression of SOCS3 is dependent on Stat 3 in macrophages
(Figure 9, a-f). SOCS3 has been shown to inhibit the LPS-induced expression of TNF- $\alpha$, IL- 6 , and iNOS in macrophages (32). Our present results show that the severe reduction in the expression of SOCS3 well correlates with the impaired IL-10-mediated suppression of the LPS-induced IL-12p40 expression in Stat 3 mutant macrophages (Figure 9). Interestingly, expression of IL-12p 40 mRNA induced by 2 -h LPS stimulation was comparable between control and Stat 3 mutant macrophages (Figure 9b). IL-12p 40 protein production during 24-h stimulation, however, was significantly increased in Stat3 mutant mice (Figures 2, 3, 5, 7). These findings may indicate that the initial LPS response was equivalent between control and Stat3 mutant macrophages, but after several hours of LPS stimulation, the difference may arise for the induction of IL-10-inducible genes associated with suppressor activity. Our findings suggest that one candidate would be IL-10-mediated expression of SOCS3 that suppresses macrophage activity. One must emphasize, however, that several other genes are also induced in response to IL-10 in macrophages (ref. 31 and our unpublished data). Therefore, there is a possibility that an additional gene product other than SOCS3 may also be responsible for the IL-10-mediated suppression of macrophages. Precise analysis of the mechanism by which IL-10 suppresses activity of myeloid cells, especially in response to LPS stimulation, would be an interesting issue, which needs to be elucidated in the future.

\section{Acknowledgments}

We thank Irmgard Förster, Kenji Sekikawa, Jeanne Magram, and Fred Alt for providing LysMcre mice, TNF$\alpha$-, IL-12-, and RAG2-deficient mice, respectively. We also thank T. Tsujimura for histopathological analysis, N. Okita for technical assistance, and E. Horita for secretarial assistance. This work was supported by grants from Special Coordination Funds, the Ministry of Education, Culture, Sports, Science and Technology, and the Japan Research Foundation for Clinical Pharmacology.

1. Podolsky, D.K. 1991. Inflammatory bowel disease. N. Engl. J. Med. 325:928-937.

2. Kuhn, R., Lohler, J., Rennick, D., Rajewsky, K., and Muller, W. 1993. Interleukin-10-deficient mice develop chronic enterocolitis. Cell. 75:263-274.

3. Mombaerts, P., et al. 1993. Spontaneous development of inflammatory bowel disease in T cell receptor mutant mice. Cell. 75:274-282.

4. Wirtz, S., et al. 1999. Cutting edge: Chronic intestinal inflammation in STAT-4 transgenic mice: characterization of disease and adoptive transfer by TNF- plus IFN- $\gamma$-producing CD4+ T cells that respond to bacterial antigens. J. Immunol. 162:1884-1888.

5. Neurath, M.F., et al. 2002. The transcription factor T-bet regulates mucosal T cell activation in experimental colitis and Crohn's disease. J. Exp. Med. 195:1129-1143.

6. Neurath, M.F., Finotto, S., and Glimcher, L.H. 2002. The role of Th1/Th2 polarization in mucosal immunity. Nat. Med. 8:567-573.

7. Strober, W., Fuss, I.J., and Blumberg, R.S. 2002. The immunology of mucosal models of inflammation. Annu. Rev. Immunol. 20:495-549.

8. Berg, D.M., et al. 1996. Enterocolitis and colon cancer in interleukin-10deficient mice are associated with aberrant cytokine production and CD4(+) TH1-like responses. J. Clin. Invest. 98:1010-1020.

9. Davidson, N.J., et al. 1996. T helper cell 1-type CD4+ T cells, but not B cells, mediate colitis in interleukin 10-deficient mice. J. Exp. Med. 184:241-251.

10. Davidson, N.J., et al. 1998. IL-12, but not IFN- $\gamma$, plays a major role in sus- 
taining the chronic phase of colitis in IL-10-deficient mice. J. Immunol. 161:3143-3149.

11. Moore, K.W., de Waal Malefyt, R., Coffman, R.L., and O'Garra, A. 2001. Interleukin-10 and the interleukin-10 receptor. Annu. Rev. Immunol. 19:683-765.

12. Asseman, C., Mauze, S., Leach, M.W., Coffman, R.L., and Powrie, F. 1999. An essential role for interleukin 10 in the function of regulatory $T$ cells that inhibit intestinal inflammation. J. Exp. Med. 190:995-1004.

13. Maloy, K.J., and Powrie, F. 2001. Regulatory T cells in the control of immune pathology. Nat. Immunol. 2:816-822.

14. Takeda, K., and Akira, S. 2000. STAT family of transcription factors in cytokine-mediated biological responses. Cytokine Growth Factor Rev. 11:199-207.

15. O'Shea, J.J., Gadina, M., and Schreiber, R.D. 2002. Cytokine signaling in 2002: new surprises in the Jak/Stat pathway. Cell. 109:S121-131.

16. Takeda, K., et al. 1997. Targeted disruption of the mouse Stat 3 gene leads to early embryonic lethality. Proc. Natl. Acad. Sci. U. S. A. 94:3801-3804.

17. Takeda, K., et al. 1998. Stat3 activation is responsible for IL-6-dependent $\mathrm{T}$ cell proliferation through preventing apoptosis: Generation and characterization of $\mathrm{T}$ cell-specific Stat3-deficient mice. J. Immunol. 161:4652-4660.

18. Akira, S. 2000. Roles of STAT3 defined by tissue-specific gene targeting. Oncogene. 19:2607-2611.

19. Levy, D.E., and Lee, C. 2002. What does Stat3 do? J. Clin. Invest. 109:1143-1148. doi:10.1172/JCI200215650.

20. Takeda, K., et al. 1999. Enhanced Th1 activity and development of chronic enterocolitis in mice devoid of Stat 3 in macrophages and neutrophils. Immunity. 10:39-49.

21. Meraz, M.A., et al. 1996. Targeted disruption of the Stat 1 gene in mice reveals unexpected physiologic specificity in the JAK-STAT signaling pathway. Cell. 84:431-442.

22. Magram, J., et al. 1996. IL-12-deficient mice are defective in IFN $\gamma$ production and type 1 cytokine responses. Immunity. 4:471-481.

23. Tagawa, Y., Sekikawa, K., and Iwakura, Y. 1997. Suppression of concanavalin A-induced hepatitis in IFN- $\gamma(-/-)$ mice, but not in TNF- $\alpha(-/-)$ mice: role for IFN- $\gamma$ in activating apoptosis of hepatocytes. J. Immunol. 159:1418-1428.

24. Hoshino, K., et al. 1999. Cutting edge: Toll-like receptor 4 (TLR4)-deficient mice are hyporesponsive to lipopolysaccharide: evidence for TLR4 as the Lps gene product. J. Immunol. 162:3749-3752.

25. Fort, M.M., Leach, M.W., and Rennick, D.M. 1998. A role for NK cells as regulators of CD4+ T cells in a transfer model of colitis. J. Immunol. 161:3256-3261.

26. Kweon, M.-N., et al. 2000. Development of antigen induced colitis in SCID mice reconstituted with spleen derived memory type CD4 CD45RB ${ }^{+}$T cells. Gut. 50:299-306.

27. Vassalli, P. 1992. The pathophysiology of tumor necrosis factors. Annu. Rev. Immunol. 10:411-452.

28. Janeway, C.A., Jr., and Medzhitov, R. 2002. Innate immune recognition. Annu. Rev. Immunol. 20:197-216

29. Akira, S., Takeda, K., and Kaisho, T. 2001. Toll-like receptors: critical proteins linking innate and acquired immunity. Nat. Immunol. 2:675-680.

30. Poltorak, A., et al. 1998. Defective LPS signaling in $\mathrm{C} 3 \mathrm{H} / \mathrm{HeJ}$ and C57BL/10ScCr mice: mutation in Tlr4 gene. Science. 282:2085-2088.

31. Lang, R., Patel, D., Morris, J.J., Rutschman, R.L., and Murray, P.J. 2002. Shaping gene expression in activated and resting primary macrophages by IL-10. J. Immunol. 169:2253-2263.

32. Berlato, C., et al. 2002. Involvement of suppressor of cytokine signaling3 as a mediator of the inhibitory effects of IL- 10 on lipopolysaccharide- induced macrophage activation. J. Immunol. 168:6404-6411

33. Oppmann, B., et al. 2000. Novel p19 protein engages IL-12p40 to form a cytokine, IL-23, with biological activities similar as well as distinct from IL-12. Immunity. 13:715-725.

34. Groux, H., et al. 1997. A CD4 ${ }^{+}$T-cell subset inhibits antigen-specific T-cell responses and prevents colitis. Nature. 389:737-742.

35. Targan, S.R, et al. 1997. A short-term study of chimeric monoclonal antibody cA2 to tumor necrosis factor alpha for Crohn's disease. N. Engl. J. Med. 337:1029-1035.

36. Kontoyiannis, D., Pasparakis, M., Pizarro, T.T., Cominelli, F., and Kollias, G. 1999. Impaired on/off regulation of TNF biosynthesis in mice lacking TNF AU-rich elements: implications for joint and gut-associated immunopathologies. Immunity. 10:387-398.

37. Plevy, S.E., et al. 1997. A role for TNF- $\alpha$ and mucosal T helper- 1 cytokines in the pathogenesis of Crohn's disease. J. Immunol. 159:6276-6282.

38. Papadakis, K.A., and Targan, S.R. 2000. Role of cytokines in the pathogenesis of inflammatory bowel diseases. Annu. Rev. Med. 51:289-298.

39. Davidson, N.J., Fort, M.M., Müller, W., Leach, M.W., and Rennick, D.M. 2000. Chronic colitis in IL-10-/- mice: insufficient counter regulation of a Th1 response. Int. Rev. Immunol. 19:91-121.

40. Kontoyiannis, D., et al. 2001. Interleukin-10 targets p38 MAPK to modulate ARE-dependent TNF mRNA translation and limit intestinal pathology. EMBO J. 20:3760-3770.

41. Rothe, J., et al. 1993. Mice lacking the tumour necrosis factor receptor 1 are resistant to TNF-mediated toxicity but highly susceptible to infection by Listeria monocytogenes. Nature. 364:798-802

42. Pfeffer, K., et al. 1993. Mice deficient for the $55 \mathrm{kd}$ tumor necrosis factor receptor are resistant to endotoxic shock, yet succumb to L. monocytogenes infection. Cell. 73:457-467.

43. Gil, M.P., et al. 2001. Biologic consequences of Stat1-independent IFN signaling. Proc. Natl. Acad. Sci. U. S. A. 98:6680-6685.

44. Ramana, C.V., et al. 2000. Regulation of c-myc expression by IFN- $\gamma$ through Stat1-dependent and -independent pathways. EMBOJ. 19:263-272.

45. Ramana, C.V., et al. 2001. Stat1-independent regulation of gene expression in response to IFN- $\gamma$. Proc. Natl. Acad. Sci. U. S. A. 98:6674-6679.

46. Ramana, C.V., Gil, M.P., Schreiber, R.D., and Stark, G.R. 2002. Stat1dependent and -independent pathways in IFN- $\gamma$-dependent signaling. Trends Immunol. 23:96-101.

47. Simpson, S.J., et al. 1998. T cell-mediated pathology in two models of experimental colitis depends predominantly on the interleukin $12 /$ signal transducer and activator of transcription (Stat)-4 pathway, but is not conditional on interferon gamma expression by T cells. J. Exp. Med. 187:1225-1234.

48. Sellon, R.K., et al. 1998. Resident enteric bacteria are necessary for development of spontaneous colitis and immune system activation in interleukin-10-deficient mice. Infect. Immun. 66:5224-5231.

49. Madsen, K.L., et al. 2000. Antibiotic therapy attenuates colitis in interleukin 10 gene-deficient mice. Gastroenterology. 118:1094-1105.

50. Hemmi, H., et al. 2000. A Toll-like receptor recognizes bacterial DNA. Nature. 408:740-745.

51. Hayashi, F., et al. 2001. The innate immune response to bacterial flagellin is mediated by Toll-like receptor 5. Nature. 410:1099-1103.

52. Gewirtz, A.T., Navas, T.A., Lyons, S., Godowski, P.J., and Madara, J.L. 2001. Cutting edge: Bacterial flagellin activates basolaterally expressed TLR5 to induce epithelial proinflammatory gene expression. J. Immunol. 167:1882-1885.

53. Rescigno, M., et al. 2001. Dendritic cells express tight junction proteins and penetrate gut epithelial monolayers to sample bacteria. Nat. Immunol. 2:361-367. 